\title{
Perbandingan hasil tangkapan tuna hand line dengan teknik pengoperasian yang berbeda di Laut Maluku
}

\author{
Catch comparison of tuna hand line with different operation techniques in Maluku Sea \\ KARYANTO $^{1,2 *}$, EMIL REPPIE ${ }^{2}$ dan JOHNNY BUDIMAN ${ }^{2}$ \\ ${ }^{I}$ Politeknik Kelautan dan Perikanan Bitung \\ ${ }^{2}$ Program Studi Pemanfaatan Sumberdaya Perikanan, Fakultas Perikanan dan Ilmu Kelautan, \\ Universitas Sam Ratulangi, Manado 95115
}

\begin{abstract}
ABSTRCT
Tuna hand lines have been widely used by fishermen in Sulawesi Sea and its surrounding to catch big pelagic species on small fishing boats. Although the gear's design has evolved over centuries, there is still potential for improving its catching efficiency and selectivity. The catching success of tuna hand line, beside baits, it is also influenced by the operation techniques. Therefore, the objective of this research was to study catch comparison of tuna hand line with different operation techniques in the water of Maluku. This research was conducted in September-November 2014 in Maluku Sea using KM. Coelacanth and KM. Melati 27 in 6 trips. Two different operating techniques of tuna hand line are: 1) natural bait with stones sinker and squid oil (KM. Coelacanth); 2) natural bait with scattered bait pockets (KM Melati). The catch of KM. Coelacanth was 111 yellow fin (Thunnus albacores), 28 big eye tuna (Thunnus obesus), 14 marlin (Makaira sp.), and 8 sailfish (Istiophorus sp.). The catch of KM. Melati 27 was 101 yellow fin tuna and 9 big eye tuna. The results of $t$ test analysis of the number of catches showed that the use of natural bait with stones sinker and squid oil not significantly different from using natural bait with scattered bait pockets
\end{abstract}

Keywords: tuna hand line, operation technique, Maluku Sea.

\begin{abstract}
ABSTRAK
Pancing ulur tuna telah digunakan secara luas oleh nelayan di Laut Sulawesi dan sekitarnya untuk menangkap ikan pelagis besar dengan kapal-kapal ukuran kecil. Walaupun konstruksinya telah berkembang sejak lama, tetapi masih memiliki potensi untuk meningkatkan efisiensi penangkapan dan selektivitasnya. Keberhasilan penangkapan tuna hand line, di samping dipengaruhi oleh umpan, juga dipengaruhi oleh teknik pengoperasian. Oleh karena itu, penelitian ini bertujuan untuk mempelajari hasil tangkapan tuna hand line dengan teknik pengoperasian yang berbeda di perairan Maluku. Penelitian ini dilakukan pada bulan September-November 2014 dengan menggunakan KM. Coelacanth dan KM. Melati 27, masing-masing sebanyak 6 trim. Dua teknik pengoperasian tuna hand line yang berbeda adalah 1. umpan alami pemberat batu dan tinta cumi (KM. Coelacanth), 2. umpan alami dengan kantong hambur (KM Melati 27). Hasil tangkapan KM. Coelacanth sebanyak 111 ekor madidihang (Thunnus albacares), 28 ekor tuna mata besar (Thunnus obesus), 14 ekor marlin (Makaira sp.), dan 8 ekor layaran (Istiophorus sp). Hasil tangkapan KM. Melati 27: 101 ekor madidihang dan 9 ekor tuna mata besar. Hasil analisis uji $\mathrm{t}$ terhadap jumlah tangkapan menunjukkan bahwa penggunaan umpan alami berpemberat batu dan tinta cumi tidak berbeda nyata dengan hasil tangkapan menggunakan umpan alami kantong hambur.
\end{abstract}

Kata-kata kunci :tuna hand line, teknik pengoperasian, Laut Maluku

\section{PENDAHULUAN}

Ikan tuna adalah salah satu jenis ikan ekonomis penting di dunia dan merupakan komoditi perikanan terbesar ketiga di Indonesia setelah udang dan ikan dasar. Ikan tuna memiliki harga yang relatif lebih mahal dibandingkan harga komoditas ikan lainnya dengan permintaan terus meningkat. Salah satu penyebab tingginya harga ikan tuna adalah

\footnotetext{
*Penulis untuk penyuratan: email: karyanto@yahoo.com
} 
kegemaran orang-orang Jepang menyantap sushi dan sasimi yang terbuat dari daging ikan tuna segar dan menyebar ke negara-negara Eropa dan Timur Tengah (Anonimous, 2011).

Salah satu alat tangkap tradisional yang sebagian besar dipakai oleh nelayan Indonesia adalah pancing ulur (hand line). Pancing ulur terdiri atas beberapa komponen, yaitu gulungan tali, tali pancing, mata pancing, dan pemberat (Subani, 1989). Selain konstruksinya sederhana, metode pengoperasian mudah, tidak memerlukan modal yang besar dan kapal khusus (Von Brandt, 1984 dalam Sudirman dan Mallawa, 2004). Keberhasilan penangkapan tuna hand line sangat dipengaruhi oleh teknik pengoperasian dari pemancing untuk mendapatkan hasil yang maksimal.

Penelitian ini bertujuan untuk mengetahui perbandingan hasil tangkapan tuna hand line dengan menggunakan teknik pengoperasian yang berbeda.

\section{METODE PENELITIAN}

Pengambilan data dilakukan di dua kapal, yaitu KM. Coelacanth milik Politeknik Kelautan dan Perikanan Bitung dan KM. Melati 27 yang berpangkalan di Pelabuhan Perikanan Samudera (PPS) Bitung, selama 6 trip pada tahun 2014. KM. Coelacanth menggunakan teknik umpan alami berpemberat batu dan tinta cumi (ulami tarumi), sedangkan KM. Melati 27 menggunakan teknik umpan alami kantong hambur (ulami kambur) dalam operasi penangkapan tuna hand line di Laut Maluku.

\section{HASIL DAN PEMBAHASAN}

\section{Alat tangkap KM. Coelacanth}

Alat tangkap yang digunakan di KM. Coelacanth, dalam operasi penangkapan adalah hand line tuna, yang terdiri dari gulungan tali, tali utama, swivel, snap, pemberat, tali penghantar (leader line) dan mata pancing, dengan daerah penangkapan di rumpon di Laut Maluku. Dalam operasi penangkapan tuna hand line dilengkapi dengan pemberat tambahan yaitu batu kali yang berfungsi untuk mempercepat tenggelamnya pancing, dan sebagai wadah untuk meletakkan umpan sayat sebagai umpan hambur, sebagai tambahan pada umpan yang dikaitkan pada mata pancing. Selain itu, umpan diberi juga ekstrak tinta cumi (cisabu) yang fungsinya untuk menarik perhatian tuna.

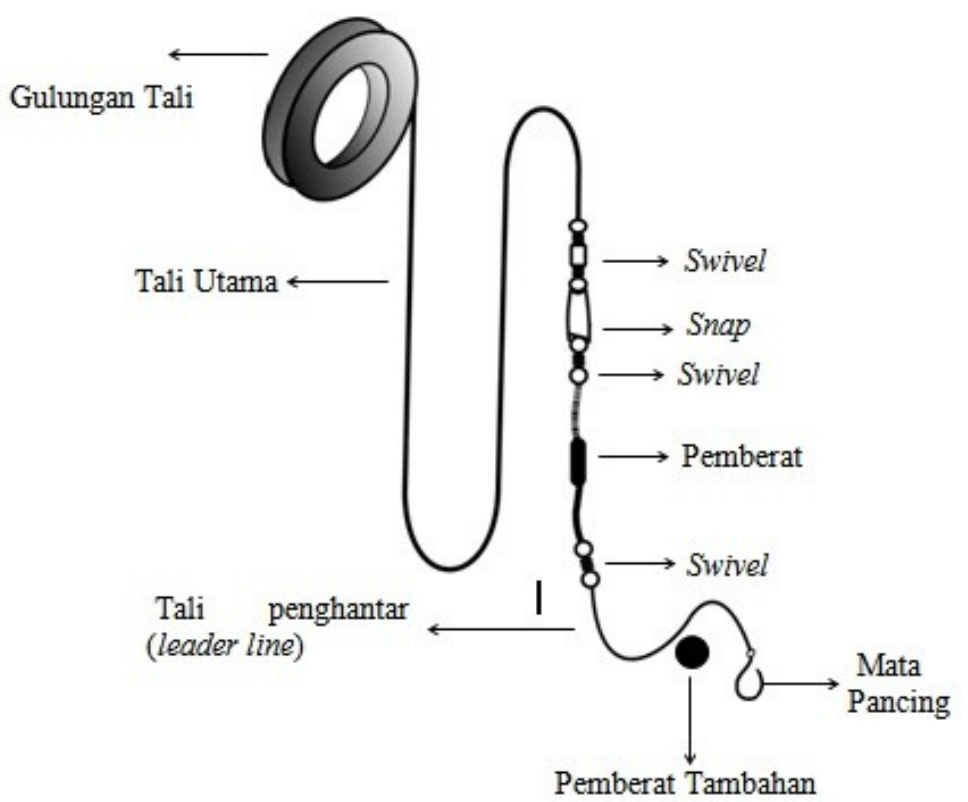

Gambar 1. Deskripsi alat tangkap hand line tuna KM. Coelacanth 


\section{Alat tangkap KM. Melati 27}

Alat tangkap yang digunakan oleh KM. Melati 27 adalah pancig ulur yang pada umumnya digunakan oleh nelayan kota Bitung yang terdiri dari gulungan tali, tali utama, swivel, pemberat, tali penghantar, mata pancing dan umpan. Alat tangkap ini tidak dilengkapi dengan snap maupun pemberat tambahan batu, dan teknik pemberian umpan tergolong berbeda dengan pancing ulur yang digunakan di KM. Coelacanth. Teknik pengoperasian hand line tuna di KM. Melati 27 dilengkapi dengan kantong plastik yang dirancang sedemikan rupa sebagai tempat atau wadah umpan yang sudah disayat maupun dipotong kecil, selain umpan utama yang dikaitkan pada mata pancing. Plastik umpan ini bentuknya seperti layang-layang yang diikatkan pada bagian bawah pemberat sehingga pada saat alat tangkap diturunkan tidak akan terlepas.

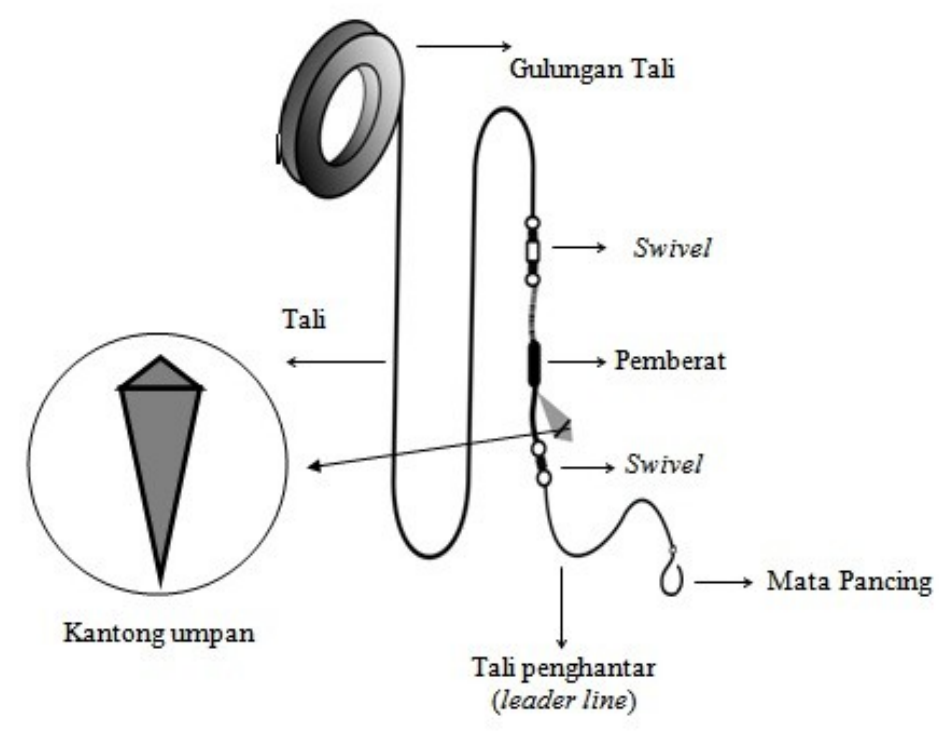

Gambar 2. Deskripsi alat tangkap hand line tuna KM. Melati 27

\section{Daerah penangkapan}

Daerah penangkapan tuna hand line KM. Coelacanth berada pada titik koordinat atau posisi yang merupakan daerah penangkapan terbanyak $00^{\circ} 02^{\prime} 00^{\prime \prime} \mathrm{LU}-125^{\circ} 54^{\prime} 00^{\prime \prime} \mathrm{BT}$ hingga $00^{\circ} 42^{\prime}$ $00^{\prime \prime} \mathrm{LU}-126^{\circ} 48^{\prime} 00^{\prime \prime}$ BT di perairan Maluku.

Daerah penangkapan tuna hand line KM. Melati 27 berada pada titik koordinat atau posisi yang merupakan daerah penangkapan terbanyak $00^{\circ} 36^{\prime}$ $00^{\prime \prime}$ LU- $125^{\circ} 57^{\prime} 00^{\prime \prime}$ BT hingga $00^{\circ} 04^{\prime} 25^{\prime \prime} \mathrm{LU}$ $126^{\circ} 15^{\prime} 23$ ” BT di Laut Maluku.

\section{Teknik penangkapan KM. Coelacanth}

Terlebih dahulu mengadakan kegiatan mencari umpan dengan cara mengail menggunakan pancing bira-bira (hand line). ikan umpan seperti tongkol, cakalang dan tuna kecil yang sudah ditangkap kemudian disayat tipis/dipotong-potong kecil dan salah satu sayatan dikaitkan pada mata pancing hingga mata pancing tidak terlihat, bersama-sama dengan kantong larutan minyak cumi. Beberapa sayatan ditambahkan dan ditaruh di atas batu kemudian diikat bersamaan dengan umpan yang sudah dikaitkan pada mata pancing. Ikatan menggunakan simpul hidup agar mudah terlepas ketika ditarik. Tali cisabu ditusukkan pada kantong minyak cumi, kemudian batu yang sudah diikat dengan mata pancing diturunkan pelanpelan ke laut pada kedalaman sekitar 50-150 m. Ketika tali pancing sudah terulur pada kedalaman yang sudah ditentukan (terasa tegang), maka tali pancing disentak sekuat mungkin agar batu dan mata pancing terlepas, pada saat itu umpan yang diikatkan pada batu akan berhamburan dan kantong minyak cumi akan menyebarkan larutan ekstrak minyak cumi, sehingga menarik perhatian ikan untuk memakannya, termasuk sayatan umpan yang dikaitkan pada mata pancing. 


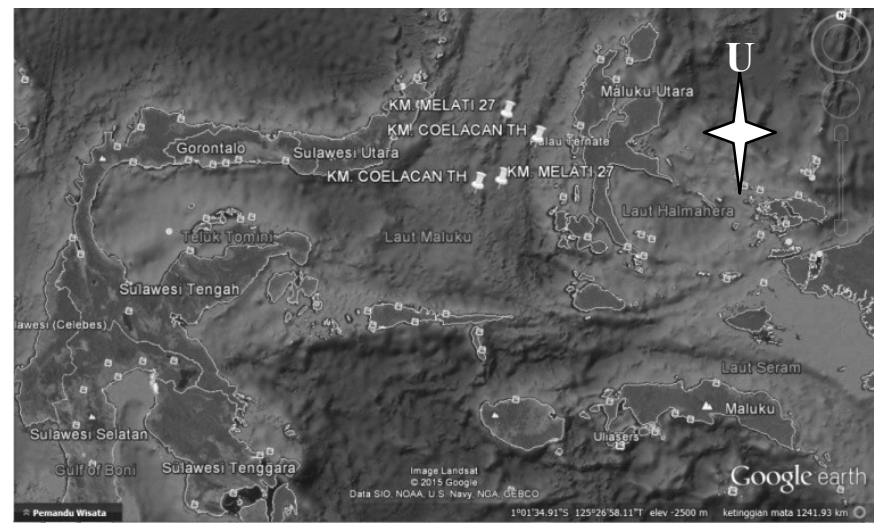

Gambar 3. Daerah penangkapan ikan (Sumber: Google Earth 2015)

Pada saat terasa ikan sudah memakan umpan, tali pancing ditarik atau digara-gara hingga ikan dipastikan sudah terkait betul kemudian tali pancing ditarik pelan-pelan mengikuti pergerakan tuna dengan hati-hati sampai tuna mendekati perahu, dan memukul pangkal kepala ikan sebelum dinaikkan dengan ganco ke atas perahu. Selanjutnya tuna dimasukkan ke dalam palka yang sudah diisi es curah. Operasi penangkapan pancing ulur dilakukan mulai jam 05.00 sampai jam 20.00, di sekitar rumpon sebagai pengumpul tuna.

\section{Teknik penangkapan KM. Melati 27}

Umpan dicari pada saat tertentu dengan cara mengail menggunakan pancing bira-bira. Ikan umpan seperti tongkol, cakalang dan tuna kecil yang sudah ditangkap kemudian disayat tipis/ dipotong-potong kecil dan salah satu sayatan dikaitkan pada mata pancing hingga mata pancing tidak terlihat. Beberapa sayatan dan potongan kecil dimasukkan dalam plastik umpan sebanyak 0.5-1 $\mathrm{kg}$ bersamaan dengan umpan yang sudah dikaitkan pada mata pancing hingga mata pancing berada di dalam urukan umpan hambur. Sebelum diturunkan ujung plastik umpan dilipat agar tetap tertutup hingga kedalaman tertentu. Kemudian umpan yang sudah disatukan diturunkan pelan-pelan ke laut pada kedalaman sekitar 50-150 m bersamaan dengan pemberat. Ketika tali pancing sudah terulur pada kedalaman yang sudah ditentukan, maka tali pancing disentak sekuat mungkin agar plastik umpan terbuka dan pada saat itu umpan berhamburan, sehingga menarik perhatian ikan untuk memakannya, termasuk sayatan umpan yang dikaitkan pada mata pancing.
Pada saat sudah terasa ikan memakan umpan tali pancing ditarik atau digara-gara hingga ikan dipastikan sudah terkait betul kemudian tali pancing ditarik pelan-pelan mengikuti pergerakan tuna dengan hati-hati untuk menghindari putusnya tali pancing sampai tuna mendekati perahu, dan memukul pangkal kepala ikan sebelum dinaikkan dengan ganco ke atas perahu. Selanjutnya tuna dimasukkan kedalam palka yang sudah diisi es curah dengan sistem chilling. Operasi penangkapan pancing ulur dilakukan mulai jam 05.00 sampai jam 18.00, di sekitar rumpon.

Trip penangkapan merupakan operasi penangkapan ikan sejak meninggalkan pangkalan menuju daerah operasi, mencari daerah operasi penangkapan ikan, sampai kembali lagi ke pangkalan asal atau tempat pendaratan. Waktu yang digunakan dalam satu trip operasi penangkapan tuna hand line ini adalah 14-15 hari.

\section{Hasil Tangkapan KM. Coelacanth}

Hasil tangkapan tuna yang diperoleh KM. Coelacanth selama 6 trip sebanyak 139 ekor, didominasi madidihang (Thunnus albacares) sebanyak 111 ekor dengan kisaran berat antara 21$63 \mathrm{~kg}$, tuna mata besar (Thunnus obesus) sebanyak 28 ekor dengan kisaran berat 35-83 kg, marlin sebanyak 14 ekor dengan kisaran berat $30-34 \mathrm{~kg}$ dan layaran sebanyak 8 ekor dengan kisaran berat $30-35 \mathrm{~kg}$.

\section{Hasil tangkapan KM. Melati 27}

Hasil tangkapan tuna yang diperoleh KM. Melati 27 selama 6 trip sebanyak 110 ekor dengan bobot 
total $3800 \mathrm{~kg}$, didominasi madidihang sebanyak 101 ekor dengan kisaran berat antara $20-45 \mathrm{~kg}$, sedangkan tuna mata besar sebanyak 9 ekor dengan kisaran berat 30-35 kg.
Analisis hasil tangkapan

Jumlah hasil tangkapan bedasarkan perlakuan teknik pengoperasian dapat dilihat pada Tabel 3 .

Tabel 1. Hasil tangkapan tuna KM. Coelacanth

\begin{tabular}{|c|c|c|c|c|c|}
\hline \multirow[b]{2}{*}{ Trip } & \multicolumn{2}{|c|}{ Hasil Tangkapan Tuna } & \multirow[b]{2}{*}{ Jumlah } & \multirow{2}{*}{$\begin{array}{l}\text { Berat } \\
(\mathrm{kg})\end{array}$} & \multirow{2}{*}{$\begin{array}{l}\text { Berat } \\
\text { Rata-rata } \\
(\mathrm{kg})\end{array}$} \\
\hline & $\begin{array}{l}\text { madidihang } \\
\text { (ekor) }\end{array}$ & $\begin{array}{l}\text { Tuna mata besar } \\
\text { (ekor) }\end{array}$ & & & \\
\hline 1 & 16 & 3 & 19 & 670 & 35.26 \\
\hline 2 & 11 & 4 & 15 & 560 & 37.33 \\
\hline 3 & 20 & 5 & 25 & 900 & 36 \\
\hline 4 & 25 & 5 & 30 & 920 & 30.67 \\
\hline 5 & 19 & 6 & 25 & 840 & 33.6 \\
\hline 6 & 20 & 5 & 25 & 750 & 30 \\
\hline Total & 111 & 28 & 139 & 4640 & \\
\hline
\end{tabular}

Tabel 2. Hasil tangkapan tuna KM. Melati 27

\begin{tabular}{|c|c|c|c|c|c|}
\hline \multirow[b]{2}{*}{ Trip } & \multicolumn{2}{|c|}{ Hasil Tangkapan Tuna } & \multirow[b]{2}{*}{ Jumlah } & \multirow[b]{2}{*}{$\begin{array}{l}\text { Berat } \\
(\mathrm{kg})\end{array}$} & \multirow{2}{*}{$\begin{array}{l}\text { Berat } \\
\text { Rata-rata } \\
\text { (kg) }\end{array}$} \\
\hline & $\begin{array}{l}\text { madidihang } \\
\text { (ekor) }\end{array}$ & $\begin{array}{l}\text { Mata besa } \\
\text { (ekor) }\end{array}$ & & & \\
\hline 1 & 14 & 1 & 15 & 550 & 36.67 \\
\hline 2 & 13 & - & 13 & 400 & 26.67 \\
\hline 3 & 22 & 2 & 24 & 850 & 56.67 \\
\hline 4 & 13 & 2 & 15 & 500 & 33.33 \\
\hline 5 & 20 & 3 & 23 & 800 & 53.33 \\
\hline 6 & 19 & 1 & 20 & 700 & 46.67 \\
\hline Total & 101 & 9 & 110 & 3800 & \\
\hline
\end{tabular}

Tabel 3. Jumlah hasil tangkapan tuna sesuai perlakuan.

\begin{tabular}{lllll}
\hline \multirow{2}{*}{ Trip } & \multicolumn{2}{l}{ Ulami Ratumi } & Ulami Kambur \\
\cline { 2 - 5 } & $\begin{array}{l}\text { Jumlah } \\
\text { (ekor) }\end{array}$ & $\begin{array}{l}\text { Berat } \\
\text { (gram) }\end{array}$ & $\begin{array}{l}\text { Jumlah } \\
\text { (ekor) }\end{array}$ & $\begin{array}{l}\text { Berat } \\
\text { (gram) }\end{array}$ \\
\hline 1 & 19 & 670 & 15 & 550 \\
2 & 15 & 560 & 13 & 400 \\
3 & 25 & 900 & 24 & 850 \\
4 & 30 & 920 & 15 & 500 \\
5 & 25 & 840 & 23 & 800 \\
6 & 25 & 750 & 20 & 700 \\
Total & 139 & 4640 & 110 & 3800 \\
\hline Rataan & 23.17 & 773 & 18.33 & 633 \\
\hline
\end{tabular}

Ikan madidihang mendominasi hasil tangkapan KM. Coelacanth yaitu sebesar $79,9 \%$ sedangkan tuna mata besar 20,1\% demikian juga pada KM.
Melati 27 madidihang 91,8\% sedangkan tuna mata besar 8,2\%. Hasil ini sesuai yang dikemukakan (Labaro, et al., 2008) bahwa tuna yang tertangkap 
di laut Maluku adalah madidihang 87,21 \%, dan tuna mata besar $9,30 \%$.

Hasil analisis jumlah tangkapan tuna hand line menunjukan bahwa $\mathrm{t}$ hitung $=0,932<\mathrm{t}$ tabel $_{0,05 ; 5}=$ 2,571; sehingga menolak $\mathrm{H}_{1}$ dan menerima $\mathrm{H}_{0}$. Hal ini menjelasan bahwa penggunaan umpan alami berpemberat batu dan tinta cumi (ulami ratumi) tidak berbeda nyata hasil tangkapannya dengan menggunakan umpan alami kantong hambur (ulami kambur). Selanjutnya analisis berat tangkapan tuna hand line juga menunjukan bahwa $\mathrm{t}$ hitung $=0,965<\mathrm{t}$ tabel ${ }_{0,05 ; 5}=2,571$; sehingga menolak $\mathrm{H}_{1}$ dan menerima $\mathrm{H}_{0}$. Hal ini menjelasan bahwa penggunaan umpan alami berpemberat batu dan tinta cumi (ulami ratumi) tidak berbeda nyata berat tangkapannya dengan menggunakan umpan alami kantong hambur (ulami kambur).

Hasil tangkapan tuna menggunakan umpan alami berpemberat batu dan tinta cumi (ulami ratumi) menunjukkan hasil yang sama dengan menggunakan umpan alami kantong hambur (ulami kambur). Kedua teknik pengoperasian tidak berbeda nyata karena tidak memberikan efek yang berbeda dengan memberikan umpan alami hambur yang sama, dan memberikan peluang yang sama terhadap tuna untuk memakan pancing di antara umpan. Hal ini terlihat pada hasil analisis perbandingan nilai tengah yang menunjukkan hasil tidak berbeda nyata atau non signifikan terhadap hasil tangkapan tuna. Perbandingan hasil tangkapan tuna menggunakan umpan alami berpemberat batu dan tinta cumi (ulamiratumi) tidak berbeda nyata dengan hasil tangkapan tuna menggunakan umpan alami kantong hambur (ulami kambur).

\section{KESIMPULAN}

1. Perbandingan hasil tangkapan tuna menggunakan umpan alami berpemberat batu dan tinta cumi (ulami ratumi) tidak berbeda nyata dengan hasil tangkapan tuna menggunakan umpan alami kantong hambur (ulami kambur). Sehingga kedua teknik pengoperasian sama baiknya untuk digunakan dalam penangkapan tuna hand line di perairan laut Maluku.

2. Teknik pengoperasian menggunakan umpan alami kantong hambur (ulami kambur) lebih ramah lingkungan dan ekonomis atau murah.

\section{DAFTAR PUSTAKA}

Anonimous. 2011. Perikanan tuna. Panduan penangkapan dan penanganan. World Wildlife Fun.

Ayodhyoa, A.U. 1981. Metode Penangkapan Ikan. Yayasan Dewi Sri, Bogor.

Baskoro, M.S dan A. Effendi. 2005. Tingkah laku ikan hubungannya dengan metode pengoperasian alat tangkap ikan. Departemen Pemanfaatan Sumberdaya Perikanan Fakultas Perikanan dan Ilmu Kelautan Institut Pertanian Bogor, Bogor.

http/www.google.earth.com/, diakses tanggal 30 Januari 2015

Labaro, I., E.M. Katiandagho, E. Reppie, dan J. Budiman. 2008. Pengaruh larutan minyak cumi (chisabu) terhadap hasil tangkapan pancing ulur tuna di Perairan sekitar pulau Batang Dua. Prosiding Konferensi Nasional Pesisir dan Lautan, pp. 782-790

Martasuganda, S. 2008. Rumah pondok ikan. Departemen Pamanfaatan Sumberdaya Perikanan dan Pusat Kajian Sumberdaya Pesisir dan Lautan. Institut Pertanian Bogor, Bogor.

Nontji, A. 2002. Laut Nusantara. Penerbit Jembatan, Jakarta.

Sadhori, N. 1985. Teknik Penangkapan Ikan. Penerbit Angkasa, Bandung.

Subani, W. dan H.R., Barus. 1989. Alat cara penangkapan ikan dan udang laut di Indonesia. Balai Penelitian Perikanan laut. Badan Penelitian dan pengembangan Pertanian. Departemen Pertanian. Jakarta.

Sudirman, H. dan A. Malawa. 2004. Teknik Penangkapan Ikan. Penerbit Rineka Cipta, Jakarta.

Usemahu, A.R. dan L.A. Tomasila. 2004. Teknik penangkapan ikan. Pusat Pendidikan dan Pelatihan Perikanan. Departemen Kelautan dan Perikanan, Jakarta. 